\title{
Assessment Protocols of Knee Muscles Spasticity Using the Isokinetic Dynamometer-A Systematic Review
}

\author{
Rui De Sousa ${ }^{1,2}$, Carolina Oliveira',2, Ana Lúcia Cruz ${ }^{1,2,3}$ \\ ${ }^{1}$ Centro Hospitalar e Universitário de Coimbra, Coimbra, Portugal \\ ${ }^{2}$ Fisio+, Health Outpatient Physiotherapy Center, Coimbra, Portugal \\ ${ }^{3}$ School of Health Sciences, University of Aveiro, Campus Universitário de Santiago, Aveiro, Portugal \\ Email: ftruisousa@gmail.com
}

How to cite this paper: De Sousa, R., Oliveira, C. and Cruz, A.L. (2021) Assessment Protocols of Knee Muscles Spasticity Using the Isokinetic Dynamometer-A Systematic Review. Open Access Library Journal, 8: e7121.

https://doi.org/10.4236/oalib.1107121

Received: December 28, 2020

Accepted: January 26, 2021

Published: January 29, 2021

Copyright $\odot 2021$ by author(s) and Open Access Library Inc.

This work is licensed under the Creative Commons Attribution International License (CC BY 4.0).

http://creativecommons.org/licenses/by/4.0/

\begin{abstract}
CONTEXT: Spasticity is an increase in resistance to the passive movement of a joint due to an abnormal increase in muscle tone. Considering the difficulty in assessing spasticity accurately, the isokinetic dynamometer is considered a valid measure for assessment of spasticity in multiple joints. OBJECTIVE: Review of assessment protocols of knee muscles spasticity using the isokinetic dynamometer. DATA SOURCES: Research was performed in the PubMed, SciELO, Academic Search Complete and Scopus databases, in English, French and Portuguese language. Studies were included when spasticity assessment protocols with isokinetic dynamometer for knee muscles were applied. STUDY SELECTION: Eligible studies were the ones assessing spasticity with an isokinetic dynamometer protocol in knee muscle groups and excluded those who failed to meet eligibility criteria. DATA EXTRACTION: Two independent reviewers applied the selection criteria to the retrieved studies to limit the number to the final list. DATA SYNTHESIS: A total of 151 studies were retrieved from the literature search and 8 articles met the inclusion criteria. Included studies assessed spasticity with the resource to the isokinetic dynamometer. All studies applied an assessment protocol using isokinetic dynamometer on knee muscle groups. CONCLUSIONS: The isokinetic dynamometer is a valuable tool in the assessment of spasticity and other conditions of tone change, offering more accurate, reliable data, easily to reproduce and to interpret. The resistance torque values have a high correlation with the Ashworth scale reflecting the clinical condition of the muscular tone.
\end{abstract}

\section{Subject Areas}

Physical Therapy 


\section{Keywords}

Assessment, Isokinetic Dynamometer, Spasticity, Muscle Tone, Knee

\section{Introduction}

A delayed consequence of a lesion affecting the upper motor neuron pathways is the appearance of some forms of motor overactivity, including spasticity [1]. Spasticity is an increase in resistance to the passive movement of a joint due to an abnormal increase in muscle tone, which is a range of amplitude and velocity dependent [1] [2].

Spasticity can be distinguished from other types of hypertonus, such as rigidity, by its sensitivity to velocity of joint motion and reaching maximum early in the range of motion. The magnitude and the pattern depend on the injury site and are usually higher in medullar lesions than cortical ones [3].

The pathophysiology underlying spasticity indicates increased stretching reflexes, excitability of either alpha and/or gamma motor neurons and abnormal reflex transmission. The role of neurotransmitters in the spasticity pathogenesis remains unclear [2] [4].

In scientific research, a broad range of methods and tools are used to assess muscle strength in individuals with spinal cord injury. The reality in clinical practice is otherwise dissimilar, where the tools available and currently used show important limitations [4].

Clinical scales such as the Ashworth Scale or the modified Ashworth are commonly used to quantify spasticity [3] [5]. These are simple and practical instruments, however, outcome measurements remain highly subjective and personal factors related to the patient may affect the results. Some studies have found Ashworth Scales to be unreliable instruments for the assessment of muscle spasticity, showing poor interrater reliability and leaving the accuracy of the outcome measurements questionable [6]. This lack of understanding or consensus may contribute to difficulties in measuring spasticity. The need for objective measurements concerning spasticity has been widely accepted.

In a literature review about instruments for measuring spinal injury muscle responses, Capelari et al. (2017) found many studies have confirmed the use of equipment like the isokinetic dynamometer and the portable dynamometer, ensuring more accurate results [4]. This computer running device enables the investigator to standardize both velocity and angle of motion, and objectively record the amount of force generated by the patient's muscles. The operation and interpretation of this method are simple and can be applied to a variety of joints and muscles [7].

This technique, which was initially developed to assess voluntary motor strength, was considered as an accurate and reliable possibility for the evaluation of spasticity in several joints [8]. 
The purpose of this review is to develop a critical view concerning the application of isokinetic dynamometer in neurological disorders with hypertonia as well as overview of measurement protocols applied. In this review, focus was defined on knee muscles because of their important role in maintaining upright posture in standing and walking, as well as in other functional activities such as squatting and stair climbing [9].

\section{Methods}

\subsection{Data Sources and Searches}

The electronic search using pre-defined search terms was restricted to English, French and Portuguese language publications retrieved from the following databases: PubMed, SciELO, Academic Search Complete and Scopus databases.

The initial research was limited to human studies published between 2000 and June 2020, however, it was extended before that because of the lack of studies to include respecting our inclusion criteria. Combinations of the following key words were used: "assessment", "isokinetic dynamometer", "spasticity", "muscle tone" and "knee". PubMed was searched using MeSH terms. The reference lists of retrieved articles were also screened for reports not identified through electronic searches.

\subsection{Inclusion and Exclusion Criteria}

To be included in this review studies must have:

1) Been published in peer-review journal as a full article or an abstract with sufficient detail to extract the main attributes of the study.

2) Adult subjects.

3) Used isokinetic dynamometer as an instrument to assess spasticity.

4) Applied a defined protocol to measure spastic knee muscle groups with sufficient detail.

Studies were excluded if:

- Data extraction was impossible;

- Measurements were not related to knee muscle groups.

\subsection{Identification of Studies}

Titles and abstracts of the retrieved articles were screened independently by RS and ALC against the eligibility criteria: Potentially eligible studies were identified and their respective full reports obtained. Full reports were then assessed separately by the two authors against the eligibility criteria. Discrepancies in judgement were resolved by consensus with consulting of $\mathrm{CO}$. The percentage of agreement between both authors was calculated.

\subsection{Assessment of Methodological Quality of Studies}

Two authors (CO and ALC) independently evaluated the quality of the studies 
according to PEDro scale for RCTs and CCTs. Discrepancies were solved by consensus. PEDro scale is a valid measure for methodological quality of the studies and its scores can confidently be subjected to parametric statistical analysis [10].

\subsection{Data Extraction, Synthesis and Analysis}

One reviewer (RS) extracted relevant data from the included studies. These included information on:

- Sample characteristics.

- Assessment protocol.

- Outcome measures.

- Results and main conclusions.

\section{Results}

A total of 151 studies were retrieved from the literature search and 69 duplicates were removed. From the remaining 82 studies, 66 were excluded base on title and abstract and 16 complete manuscripts were retrieved and assessed for inclusion by RS and ALC against the eligibility criteria (Figure 1). After this, 8 articles were included in this review [7] [8] [9] [11] [12] [13] [14] [15]. The percentage of agreement between both reviewers was $92 \%$ and discrepancies were solved by consensus.
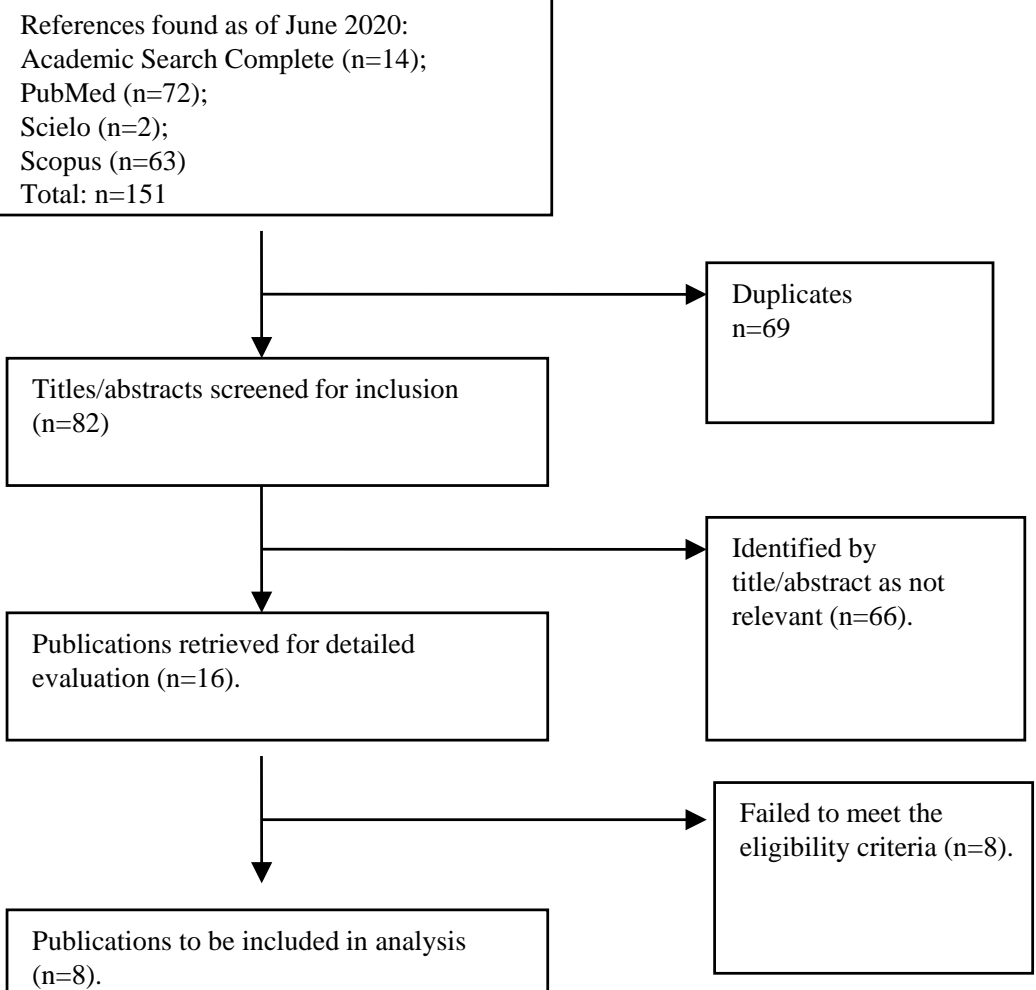
$(n=8)$.

Figure 1. Flow chart for the systematic review. 


\subsection{Assessment of Methodological Quality of Studies}

Concerning external validity, all studies with the exception of one [7] define and present inclusion criteria for participants. Related to internal validity, only two studies [12] [15] randomized the sequence for the measurements. Blinding procedures were absent in all the studies. Although relevant for methodological quality, fact remains that the type of protocol we are considering for inclusion does not allow rigorous blinding procedures, nevertheless, data measuring is processed in a computer-based instrument, opaque to influences. Considering result reports, all studies present the results initially proposed in a clear and objective way (Table 1).

Table 1. Methodological quality checklist.

\begin{tabular}{|c|c|c|c|c|c|c|c|c|}
\hline & \multicolumn{8}{|c|}{ Authors } \\
\hline & $\begin{array}{l}\text { Perell, } \\
\text { Scremin \& } \\
\text { Kunkel, } \\
\text { (1996) }\end{array}$ & $\begin{array}{l}\text { Akman et } \\
\text { al., (1999) }\end{array}$ & $\begin{array}{l}\text { Franzoi, } \\
\text { Castro \& } \\
\text { Cardone, } \\
\text { (1999) }\end{array}$ & $\begin{array}{l}\text { Kakebeeke et } \\
\text { al., (2002) }\end{array}$ & $\begin{array}{l}\text { Supraja \& } \\
\text { Singh, } \\
(2003)\end{array}$ & $\begin{array}{l}\text { Moreau, Li, } \\
\text { Geaghan \& } \\
\text { Damiano, } \\
\text { (2009) }\end{array}$ & $\begin{array}{l}\text { Boudarham } \\
\text { et al., (2014) }\end{array}$ & $\begin{array}{l}\text { Hameau et } \\
\text { al., (2014) }\end{array}$ \\
\hline \multicolumn{9}{|l|}{ Pedro scale } \\
\hline 1) eligibility criteria were specified & $\sqrt{ }$ & $x$ & $\sqrt{ }$ & $\sqrt{ }$ & $\sqrt{ }$ & $\sqrt{ }$ & $\sqrt{ }$ & $\sqrt{ }$ \\
\hline $\begin{array}{l}\text { 2) subjects were randomly allocated to } \\
\text { groups (in a crossover study, subjects } \\
\text { were randomly allocated an order in } \\
\text { which treatments were received) }\end{array}$ & $x$ & $x$ & $x$ & $\sqrt{ }$ & $x$ & $x$ & $x$ & $\sqrt{ }$ \\
\hline 3) allocation was concealed & $x$ & $x$ & $x$ & $x$ & $x$ & $\times$ & $x$ & $x$ \\
\hline $\begin{array}{l}\text { 4) the groups were similar at baseline } \\
\text { regarding the most important } \\
\text { prognostic indicators }\end{array}$ & $\sqrt{ }$ & $\sqrt{ }$ & $x$ & $\sqrt{ }$ & $\sqrt{ }$ & $x$ & $x$ & $x$ \\
\hline 5) there was blinding of all subjects & $x$ & $x$ & $x$ & $x$ & $x$ & $x$ & $x$ & $x$ \\
\hline $\begin{array}{l}\text { 6) there was blinding of all therapists } \\
\text { who administered the therapy }\end{array}$ & $x$ & $x$ & $x$ & $x$ & $x$ & $x$ & $x$ & $x$ \\
\hline $\begin{array}{l}\text { 7) there was blinding of all assessors } \\
\text { who measured at least one key outcome }\end{array}$ & $x$ & $x$ & $x$ & $x$ & $x$ & $x$ & $x$ & $\times$ \\
\hline $\begin{array}{l}\text { 8) measures of at least one key outcome } \\
\text { were obtained from more than } 85 \% \text { of } \\
\text { the subjects initially allocated to groups }\end{array}$ & $\sqrt{ }$ & $\sqrt{ }$ & $\sqrt{ }$ & $x$ & $\sqrt{ }$ & $\sqrt{ }$ & $\sqrt{ }$ & $\sqrt{ }$ \\
\hline $\begin{array}{l}\text { 9) all subjects for whom outcome } \\
\text { measures were available received the } \\
\text { treatment or control condition as } \\
\text { allocated or, where this was not the } \\
\text { case, data for at least one key outcome } \\
\text { was analysed by "intention to treat" }\end{array}$ & $\sqrt{ }$ & $\sqrt{ }$ & $\sqrt{ }$ & $\sqrt{ }$ & $\sqrt{ }$ & $\sqrt{ }$ & $\sqrt{ }$ & $\sqrt{ }$ \\
\hline $\begin{array}{l}\text { 10) the results of between-group } \\
\text { statistical comparisons are reported for } \\
\text { at least one key outcome }\end{array}$ & $\sqrt{ }$ & $\sqrt{ }$ & $\sqrt{ }$ & $\sqrt{ }$ & $\sqrt{ }$ & $\sqrt{ }$ & $\sqrt{ }$ & $\sqrt{ }$ \\
\hline $\begin{array}{l}\text { 11) the study provides both point } \\
\text { measures and measures of variability } \\
\text { for at least one key outcome }\end{array}$ & $x$ & $x$ & $x$ & $x$ & $x$ & $x$ & $x$ & $x$ \\
\hline
\end{tabular}

$\sqrt{\text { yes}} / \times$ no. 


\subsection{Participants}

The retrieved 8 articles included a total of 205 participants. Sample size varied between a minimum of 12 [11] and a maximum of 33 participants [7].

\subsection{Inclusion Criteria for Participants}

Most of the studies established inclusion criteria in the studies based on spasticity evaluation with Ashworth scale [7] [11] [13] [14] or Modified Ashworth Scale [8] [15] while one study used the Gross Motor Function Classification System [9] or ASIA [12] [13]. Some studies mentioned absence of knee orthopaedic problems [8] [9] [11] [13] [15] and absence of antispastic medication [8] [9] [15].

\subsection{Outcome Variables and Measurement Instruments}

All studies used the isokinetic dynamometer to collect data regarding spasticity [7] [8] [9] [11] [12] [13] [14] [15]. The Ashworth scale was used, in most studies [7] [8] [11] [13] [14] [15], and two studies used the ASIA scale [12] [13]. EMG was used in three [7] [8] [9] of the studies analysed.

\subsection{Type of Protocol}

The assessment was performed with the patient seated in the chair of the isokinetic dynamometer, with the hips fixed between $70^{\circ}$ and $90^{\circ}$ flexion, using straps across the chest, the pelvis and upper thigh in all but one study [12]. The rotational axis of the dynamometer was placed in line with the axis of flexion/extension movement of the knee. The lower leg was fixed to the lever of the dynamometer between $2 \mathrm{~cm}$ to $3 \mathrm{~cm}$ above the lateral malleolus. Akman et al. (1999) only refer to seated position lacking more detail. [7] Kakebeeke et al. (2002) measured every patient in two defined, stretched positions. In the seated position, the same protocol of the other studies was used. In the supine position, patients were positioned with the lower leg hanging over the edge of the seat; the pelvis was fixated with a strap over the anterior superior iliac spine; the lower leg was fixed with straps $4 \mathrm{~cm}$ above the lateral malleolus. The other leg was placed with flexed knee and hip with the foot on the table. This leg was held in position by one of the researchers [12].

Gravity correction was performed to account for the weight of the limb by all the researchers.

Previous to spasticity assessment, participants were distributed between control and experimental groups using assessment instruments like ASIA or Ashworth scale and assessment protocols were predefined in the isokinetic dynamometer (Table 2).

\subsection{Comparisons and Outcome}

Of the analysed studies, four [7] [11] [13] [14] [15] found a correlation between isokinetic dynamometer measures and other instruments, like Ashworth scale. 
Table 2. Studies content summary.

\begin{tabular}{|c|c|c|c|c|c|}
\hline Authors & Sample & Inclusion criteria & Assessment tools & $\begin{array}{l}\text { Evaluation protocol in the } \\
\text { isokinetic dynamometer }\end{array}$ & Results/Conclusions \\
\hline $\begin{array}{l}\text { Perell, Scremin } \\
\text { \& Kunkel, } \\
\text { (1996) }\end{array}$ & $\begin{array}{l}\text { - } 11 \text { patients with } \\
\text { spastic spinal cord } \\
\text { injury; } \\
\text { - } 6 \text { patients with flaccid } \\
\text { spinal cord injury; } \\
\text { - } 10 \text { healthy subjects } \\
\text { (control group); } \\
\text { - Average time after } \\
\text { injury: spastic group - } \\
9.00 \pm 5.80 \text { years; flaccid } \\
\text { group: } 17.67 \pm 8.63 \\
\text { years; } \\
\text { - Variation of injury } \\
\text { level: C5 - L1 (spastic } \\
\text { group) and T11 - L1 } \\
\text { (flaccid group). }\end{array}$ & $\begin{array}{l}\text { - Medically and } \\
\text { neurologically stable; } \\
\text { - Spastic muscle tone } \\
\text { varying in degree } \\
\text { from mild to severe } \\
\text { based on the physical } \\
\text { examination } \\
\text { (Ashworth scale = } \\
2 \text { - 4); } \\
\text { - Lack of muscle tone } \\
\text { in the flaccid subjects } \\
\text { confirmed by } \\
\text { physical examination } \\
\text { (Ashworth scale =0). }\end{array}$ & $\begin{array}{l}\text {-Ashworth scale; } \\
\text {-Isokinetic } \\
\text { dynamometer } \\
\text { Model: Kin-Com } \\
\text { model 500R, } \\
\text { Chattacx Co., } \\
\text { Chattanooga, TN. } \\
\end{array}$ & $\begin{array}{l}\text { - Passive range of } \\
\text { motion performed: } \\
50^{\circ}, \text { between } 25^{\circ} \\
\text { and } 75^{\circ} \text { knee flexion; } \\
\text { - Angular velocities } \\
\text { of passive movement: } \\
30,60,120^{\circ} / \mathrm{s} \text {; } \\
\text { - Subject position: } \\
\text { seated on a chair, } \\
\text { hip maintained at } \\
90^{\circ} \text { flexion } \\
\text { - Instructions to subjects: } \\
\text { n.d.; } \\
\text {-Number of repetitions: } \\
10 \text { to } 12 \text { repetitions (for } \\
\text { flexion and extension of the } \\
\text { knee). For data analysis, } \\
\text { values collected in the } 5 \\
\text { average repetitions were } \\
\text { used; } \\
\text { - Spasticity measurement: } \\
\text { Average torque of the } 5 \\
\text { intermediate repetitions } \\
\text { for maximum peak (Tmax) } \\
\text { and the sum of } 4 \text { consecutive } \\
\text { peaks (Tsum), for each speed } \\
\text { for each phase (flexion and } \\
\text { extension) separately. }\end{array}$ & $\begin{array}{l}\text { Maximum peak flexion } \\
\text { (Tmax FLX) could be used to } \\
\text { distinguish a homogenous } \\
\text { population of complete, } \\
\text { spastic SCI subjects from } \\
\text { flaccid SCI subjects, and from } \\
\text { normal able-bodied subjects. } \\
\text { Tmax FLX of the spastic } \\
\text { group was significantly lower } \\
\text { at } 60 \text { and } 120^{\circ} / \mathrm{s} \text { than that of } \\
\text { the other two groups. }\end{array}$ \\
\hline
\end{tabular}

\begin{tabular}{|c|c|c|c|c|c|}
\hline $\begin{array}{l}\text { Akman et al., } \\
\text { (1999) }\end{array}$ & $\begin{array}{l}\text { - } 33 \text { patients with spinal } \\
\text { cord injury, with } \\
\text { different degrees of } \\
\text { hypertonia in the } \\
\text { clinical examination: } 28 \\
\text { paraplegics (18 } \\
\text { complete, } 10 \\
\text { incomplete); and } 5 \\
\text { quadriplegics ( } 3 \\
\text { complete and } 2 \\
\text { incomplete); } \\
\text { - } 14 \text { healthy subjects } \\
\text { (control group); } \\
\text { - Average time after } \\
\text { injury: } 13.5 \pm 7.6 \\
\text { months. }\end{array}$ & $\begin{array}{l} \\
\text { - Clinical } \\
\text { examination } \\
\text { (Ashworth scale = 1- } \\
\text { 4). } \\
\end{array}$ & $\begin{array}{l}\text {-Ashworth scale; } \\
\text {-Isokinetic } \\
\text { dynamometer } \\
\text { Model: Cybex } \\
\text { Norm II, Lumex } \\
\text { Inc. } \\
\text { Ronkomkoma, } \\
\text { NY, USA. } \\
\text {-EMG. }\end{array}$ & $\begin{array}{l}\text { - Passive range of } \\
\text { motion performed: } \\
\text { not referred; } \\
\text { - Angular velocities } \\
\text { of passive movement: } \\
15,30,60,90 \text { and } 120^{\circ} / \mathrm{s} \text {; } \\
\text { - Subject position: } \\
\text { measurements were done } \\
\text { in the sitting position; } \\
\text { - Instructions to subjects: } \\
\text { n.d.; } \\
\text { - Number of repetitions: } \\
5 \text { passive articular } \\
\text { movements for each } \\
\text { angular velocity; } \\
\text { - Spasticity measurement: } \\
\text { Determined by recording } \\
\text { the } 5 \text { negative peak torque } \\
\text { values (foot. pounds - ft.lb) } \\
\text { at all speeds and joint } \\
\text { movements using, for analysis, } \\
\text { the maximum torque peak } \\
\text { (mT) and the sum of the } 5 \\
\text { torque peak ( } \sum \mathrm{T} \text { ). }\end{array}$ & $\begin{array}{l}\text { The results showed that the } \\
\text { average } \mathrm{mT} \text { and } \Sigma \mathrm{T} \text { values } \\
\text { were positively correlated } \\
\text { with the Ashworth grades. In } \\
\text { knee flexion-extension and } \\
\text { ankle dorsal flexion, patients } \\
\text { with Ashworth grade one did } \\
\text { not differ from control group } \\
\text { in their torque values while } \\
\text { they differ significantly in hip } \\
\text { abduction (P50.05), and in } \\
\text { knee flexion-extension, the } \\
\text { difference between torque } \\
\text { values of patients with } \\
\text { Ashworth grade } 2 \text { and control } \\
\text { group was insignificant. } \\
\text { There was no significant } \\
\text { linear correlation between } \\
\text { torque values and velocity of } \\
\text { joint motion in either the } \\
\text { patient or the control group. }\end{array}$ \\
\hline
\end{tabular}




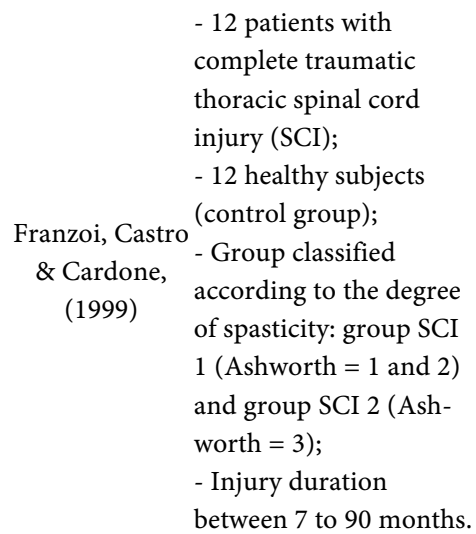

- 12 patients with complete traumatic injury (SCI);

-12 healthy subjects - Group classified according to the degree of spasticity: group SCI and group SCI 2 (Ashworth = 3);

between 7 to 90 months.

- Complete traumatic thoracic spinal cord -Ashworth scale; injury (ASIA A) with -Isokinetic clinically detectable dynamometer spasticity (Ashworth Model: Cybex Scale $1 \pm 3$ ); $\quad 6000^{\circ}$, - Without previous history of knee trauma nor disease. Ronkokoma, NY, USA.

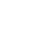

\section{- Passive range of motion performed: $25^{\circ}$ extension and $85^{\circ}$ flexion;}

- Angular velocities of passive movement: 30,60 and $120 \%$ (for each range of motion) whit rest periods 10s;

- Subject position: seated with chest and thigh restrained by straps. Attachment made $4 \mathrm{~cm}$ above the lateral malleolus;

- Instructions to subjects: able-bodied subjects were asked , not to interfere on the passive movements of the dynamometer keeping their limbs relaxed; - Number of repetitions: 5 passive joint movements were performed for flexion and extension with 10 s rest periods; - Spasticity measurement: Average peak torque of flexion and extension movement.
It was possible, with the isokinetic examination (at displacements of 60 and 1208 per second), to determine the resistance of passive movement as a measure of muscular tone in a group of patients with spastic SCI and a control group of able-bodied subjects.

$\begin{array}{clll} & \begin{array}{l}\text { 20 patients with } \\ \text { complete motor spinal }\end{array} & \text { - Motor complete } & \\ \text { cord injury; } & \text { spinal cord lesion } & \\ & \text { - Diagnostic with a } & \text { - Spasticity in the } & \text {-Isokinetic } \\ \text { Kakebeeke et } & \text { minimum time of } 4 & \text { lower limbs, who did } & \text { Model: Cybex } \\ \text { al., (2002) } & \text { months; } & \text { not suffer } & \text { Norm II, Lumex } \\ & \text { - Variable injury level } & \text { from any joint } & \text { Inc. } \\ \text { between C5 and T6; } & \text { problems or severe } & \text { Ronkomkoma, } \\ & \text { - Mean time post injury } & \text { osteoporosis and } & \text { NY, USA. } \\ \text { 7.1 year (SD 8.6; 0.3 } \pm & \text { had a hip extension } & \\ \text { 22.6). } & \text { of } 0^{\circ} . & \end{array}$

- Passive range of motion performed: Variable test range between $90^{\circ}$ and $120^{\circ}$;

- Angular velocities of passive movement: $10 \%$ and $120 \%$; - Subject position: two defined stretched positions:

1) Sitting position:hips in $90^{\circ}$ flexion and lower legs hanging over the edge of the seat. Attachment $4 \mathrm{~cm}$ above the lateral malleolus.

2) Supine position: lower leg hanging over the edge of the seat; speed were more stable and pelvis fixated with a strap over higher, with the exception of the spinae iliacae anteriores superiors, lower leg fixed $4 \mathrm{~cm}$ above the lateral malleolus. The other leg was placed with flexed knee and hip with the foot on the exten table;

The correlation coefficients between the first and second protocol for the low speed were only moderate and not always significant.

The correlation coefficients of the movements at the higher the correlation of the extensors in sitting and the flexors in supine position. The excitability of the - Instructions to subjects: n.d.; the sitting position, for the - Number of repetitions: Movement performed 2 times from flexion to extension and flexors it was reverse. In the sitting position it was easier to elicit spasms in the vice versa at $10 \%$ and 4 times at hamstring muscles. $120 \%$ s; with a 5 min break;

- Spasticity measurement: Maximum torque peak from 2 slow reps and 4 fast reps - sum of peak torque for slow repetitions and fast repetitions; 


$\begin{array}{cl} & -12 \text { patients with } \\ & \text { clinically detectable } \\ & \text { spasticity: } 10 \text { with } \\ \text { Supraja \& } & \text { complete traumatic } \\ \text { Singh, (2003) } & \text { spinal cord injury; } 2 \\ & \text { with hemiplegia after } \\ & \text { stroke; } \\ & -12 \text { healthy subjects } \\ & \text { (control group). }\end{array}$

- 12 patients with nically detectable - Clinically detectable spasticity;

- Without any history suggestive of knee trauma or disease. (control group) modified; -Isokinetic dynamometer
Moreau, Li,

Geaghan \& $\quad-17$ patients with

Damiano, cerebral palsy (CP).

(2009) -Ashworth scale attachment $5 \mathrm{~cm}$ above the

- Passive range of motion

performed:

not referred;

- Angular velocities of passive movement:

30,60 and $120 \%$ s;

- Subject position: seated with restraining straps at the level of the chest, around the abdomen and thigh. Distal lateral malleolus; - Instructions to subjects: able bodied subjects were asked to keep their knees relaxed and not to interfere with the passive movement of the knee joint;

- Number of repetitions:

Performed 5 repetitions for each speed with 10 s rest period;

- Spasticity measurement: Peak maximum torque value measured in $\mathrm{ft} . \mathrm{lb}$ (foot-pounds);
The maximum peak torque was higher in cases than controls at all angular speeds tested $(\mathrm{p}<0.05)$. These values increased with increase in speed of movement of the limb. Flexion torque (FT) at 3 degree per second was significantly higher than the extension torque (ET) $(\mathrm{p}<0.05)$. In the control group there as no significant difference between FT and ET. Spasticity could be quantified isokinetic dynamometer which correlated well with Ashworth Scale.

- Passive range of motion performed:

Comfortable range

for the patient;

- Ambulatory CP patients either with or without assistive devices;

- Within Gross Motor Function Classification System Levels I, II, and III;

- No history of orthopedic surgery within 12 months prior to the testing; - No Botulinum toxin -Isokinetic dynamometer Model: Biodex Medical Systems Incorporated, Shirley, NY, USA; -EMG.

injections within 6 months prior to the testing;

- Absence of knee pain.

\section{- Angular velocities of} passive movement:

$5,10,30,60,90$ and $120 \%$ s;

- Subject position: seated in the Biodex chair; - Instructions to subjects: the subjects were instructed to relax their muscles;

- Number of repetitions: erformed 3 passive repetitions with 30s of rest between each speed;

- Spasticity measurement: Hamstring and quadriceps spasticity measured with peak resistance during passive knee extension and passive flexion, respectively.
Higher hamstring cocontraction and spasticity and lower hamstring strength were associated with lower levels of hamstring fatigue. Higher quadriceps cocontraction and lower quadriceps strength were the most predictive of lower levels of quadriceps fatigue. 


\begin{tabular}{|c|c|c|c|c|c|}
\hline $\begin{array}{c}\text { Boudarham et } \\
\text { al., (2014) }\end{array}$ & $\begin{array}{l} \\
\\
\text { - } 18 \text { hemiplegic patients; } \\
\pm 31.2 \text { month. } \\
\end{array}$ & $\begin{array}{l}\text { - Over } 18 \text { years old; } \\
\text { - More than } 6 \\
\text { months post stroke } \\
\text { (chronic-phase); } \\
\text { - Score } \geq 1+\text { on } \\
\text { modified Ashworth } \\
\text { scale (MAS) for the } \\
\text { quadriceps } \\
\text { muscles; } \\
\text { - Ability to walk } \\
10 \text { m without } \\
\text { walking aids; } \\
\text { - No use of } \\
\text { antispastic } \\
\text { medications for } \\
6 \text { months before } \\
\text { inclusion; } \\
\text { - No orthopedic } \\
\text { surgery in the } \\
\text { last } 6 \text { months. }\end{array}$ & $\begin{array}{l}\text {-Isokinetic } \\
\text { dynamometer } \\
\text { Model: } \\
\text { ConTrex-MJ, } \\
\text { Contrex, CMV } \\
\text { AG, Dübendorf, } \\
\text { Switzerland; } \\
\text {-EMG. }\end{array}$ & $\begin{array}{l}\text { movement: } \\
90,180 \text { and } 240 \% \text {, randomly; } \\
\text { - Subject position: } \\
\text { seated in the chair of the } \\
\text { isokinetic dynamometer in a } \\
\text { position of } 85 \text { hip flexion and } \\
\text { the lower legs hanging over } \\
\text { the edge of the seat. Lower } \\
\text { leg fixed } 3 \text { cm above the } \\
\text { lateral malleolus; } \\
\text { - Instructions to subjects: } \\
\text { subjects were instructed to relax } \\
\text { during the trials and to close } \\
\text { their eyes; } \\
\text { - Number of repetitions: } 5 \\
\text { continuous passive movements } \\
\text { of knee flexion; } \\
\text { - Spasticity measurement: } \\
\text { - Maximum peak torque } \\
\text { resistance for each reflex } \\
\text { contraction was determined by } \\
\text { the lowest value on the torque } \\
\text { curve. } \\
\text { - Work calculated in joules by } \\
\text { adding the area under the torque } \\
\text { curve. }\end{array}$ & $\begin{array}{l}\text { Peak resistive torque during } \\
\text { the passive movements at } \\
\text { each velocity was not mod- } \\
\text { ified by the fatigue protocol, } \\
\text { neither was the work slope. } \\
\text { Normalized root mean square } \\
\text { (RMS) values of the rectus } \\
\text { femoris (RF) and vastus } \\
\text { lateralis (VL) muscles during } \\
\text { passive trials were also similar } \\
\text { before and after the fatigue } \\
\text { protocol. }\end{array}$ \\
\hline $\begin{array}{c}\text { Hameau et al., } \\
\text { (2014) }\end{array}$ & $\begin{array}{l}\text { - } 14 \text { patients with } \\
\text { chronic spastic } \\
\text { hemiparesis after stroke } \\
\text { (12 with right } \\
\text { hemiparesis and } 2 \text { with } \\
\text { left hemiparesis); } \\
\text { - Time since stroke: } 90 \\
\pm 36 \text { months. }\end{array}$ & $\begin{array}{l}\text { - Over } 18 \text { years old; } \\
\text {-Hemiparesis } \\
\text { following stroke for } \\
\text { more than } 6 \text { months; } \\
\text { - Score } \geq 1 \text { on the } \\
\text { MAS for the } \\
\text { quadriceps muscle; } \\
\text { - Inappropriate RF } \\
\text { EMG activity during } \\
\text { mid-swing phase of } \\
\text { the gait cycle; } \\
\text { - Able to walk } 10 \mathrm{~m} \\
\text { without supportive } \\
\text { devices; } \\
\text { - Last BoNT-A } \\
\text { injection more } \\
\text { than } 4 \text { months } \\
\text { before inclusion; } \\
\text { - No surgical } \\
\text { interventions in } \\
\text { the lower limb in } \\
\text { the last } 6 \text { months. }\end{array}$ & $\begin{array}{l} \\
\\
\text {-Duncan Ely Test; } \\
\text {-Modified } \\
\text { Ashworth Scale } \\
\text { (MAS); } \\
\text {-Isokinetic } \\
\text { dynamometer } \\
\text { Model: ConTrex } \\
\text { AG, Dübendorf, } \\
\text { Switzerland. } \\
\end{array}$ & $\begin{array}{l}\text { - Passive range of motion } \\
\text { performed: } 70^{\circ} \text { (from } 20^{\circ} \text { to } 90^{\circ} \\
\text { knee flexion); } \\
\text { - Angular velocities of passive } \\
\text { movement: } 10,90,180 \text { and } \\
240^{\circ} / \mathrm{s} \text { ( } 1 \text { minute rest after each } \\
\text { speed); } \\
\text { - Subject position: subjects were } \\
\text { seated on the dynamometer chair } \\
\text { with the back support inclined } \\
15^{\circ} \text { posterior to the vertical } \\
\text { plane. Distal fixation } 2 \\
\text { centimeters proximal to the } \\
\text { lateral malleolus; } \\
\text { - Instructions to subjects: n.d.; } \\
\text { - Number of repetitions: } 5 \\
\text { continuous passive movements } \\
\text { of knee flexion; } \\
\text { - Spasticity measurement: } \\
\text { Incline of the torque - speed } \\
\text { curve. Peak resistive torque } \\
\text { defined as the maximum } \\
\text { resistance force generated } \\
\text { during the test, averaging the } 5 \\
\text { tests. }\end{array}$ & $\begin{array}{l} \\
\text { The MAS score of the RF } \\
\mathrm{r} \text { decreased significantly after } \\
\text { botulinum toxin injection } \\
\text { (BoNT-A) }(\mathrm{P}=0.027) . \\
\text { Peak resistive torque was } \\
\text { significantly decreased at the } \\
\text { three tested velocities after } \\
\text { BoNT-A injection }\left(90^{\circ} / \mathrm{s}: \mathrm{P}=\right. \\
0.007 ; 180^{\circ} / \mathrm{s}: \mathrm{P}=0.035 \text { and } \\
\left.240^{\circ} / \mathrm{s}: \mathrm{P}=0.023\right) .\end{array}$ \\
\hline
\end{tabular}

- Passive range of motion performed: the passive range of the patient is used without pain induction;

- Angular velocities of passive movement

90,180 and $240 \%$ s, randomly;

Subject position

seated in the chair of the

isokinetic dynamometer in a position of 85 hip flexion and the lower legs hanging over the edge of the seat. Lower above the walking aids;

No use of medications for before - No orthopedic surgery in the last 6 months.

- Over 18 years old quadriceps muscle;

patients with chronic spastic mid-swing phase of (12 with right the gait cycle; devices; injection more the lower limb in

n.d. - not defined. 
Concerning fatigue as a factor affecting spasticity, as measured by isokinetic dynamometer, two studies found no difference [8] [9]. One study [12] compared two measuring protocols (seated and supine position) and found the excitability of the extensors of the knee was higher in the supine than in the sitting position, with a reverse result for the flexors In the sitting position, being easier to elicit spasms in the hamstring muscles.

\section{Discussion}

Spasticity assessment using isokinetic dynamometer has been widely accepted as accurate and practical. Many authors have recurred to this particular form of outcome measurement associated with other instruments (like Ashworth scale) in order to increase outcome measurement reliability. Accuracy in outcome measurement is very important to allow objective interpretation along with more efficient planning for treatment programs.

Studies assessing hypertonia rely on an accurate definition and selection for participants, as well as on precisely defined assessment protocols considering all outcomes to measure with the isokinetic dynamometer (passive range of motion, angular velocity for PROM, number of repetitions for each velocity as well as methods for measuring spasticity through data interpretation for peak torque).

Boudarham et al. (2014), studying the relation between spasticity and fatigue found that repeated concentric contraction induced fatigue does not affect spasticity as assessed through peak torque resistance in any angular velocity.

This conclusion refutes previous conclusions by Franzoi, Castro \& Cardone (1999), that found fatigue decreases stretching reflex, analysing a series of 5 repetitions for angular movement at any angular velocity in the knee.

Kakebeeke et al., (2002) measure spasticity on knee muscular groups in two different positions, sitting and in supine. The purpose of this study was to understand the importance of muscle length as a factor to consider when assessing spasticity. For both groups, flexors and extensors, torques obtained where significantly higher in elongated position leading to the assumption that measures are more reliable when the muscle is in this position.

This fact is logical if considered that the elongated muscle offers higher resistance to the passive mobilization, hence, that spasticity is increased. Therefore, the outcome assessment position influences the results, once the muscle position affects the response to passive movement.

Considering hip position influences the assessment and, consequently, the outcomes, when measuring knee muscle spasticity, studies must define protocols where hip position is considered and registered when performing isokinetic dynamometer testing. Perell, Scremin \& Kunkel. (1996) referred the subjects were positioned with $90^{\circ}$ hip flexion, Franzoi, Castro \& Cardone (1999) leaves the register of sitting position with the back of the chair at $85^{\circ}$ and Moreau, Li, Geaghan \& Damiano, (2009) consider a sitting position, reclined, in a $70^{\circ}$ hip flexion angle. More recent studies, measured spasticity in hip position of $85^{\circ}$ [8] or rec- 
lined back in a $15^{\circ}$ vertical angle [15]. The improved definition of hip position while measuring spasticity raises the importance of considering this factor as a possible influence on studies results.

Generally, isokinetic dynamometry has been showed to be a useful method when quantifying spasticity. In order to easily apply this assessment in a clinical context, Perell, Scremin \& Kunkel., (1996) found the measurement at $120^{\circ} / \mathrm{s}$ is sufficient to assess spasticity. Franzoi, Castro \& Cardone (1999) reenforce this when describing the highest difference between torque averages occurrs at $120 \%$, highlighting that lower velocities ( 30 and $60 \%$ s) are not accurate to detect mild degrees of spasticity.

Considering Ashworth scale supplies data about spasticity assessment, although with low accuracy, most studies stablished this scale as a reference to compare results measured by the isokinetic dynamometer. Considering the final analysis of the outcome measurements, one may considerer the dynamometer is a reliable instrument to asses spasticity with good test-retest reliability allowing a clinical application to assess patient outcomes throughout a rehabilitation program.

More studies are suggested, particularly comparing measurements for spastic muscles with resource to other instruments like EMG to better define reliability for isokinetic dynamometer.

\section{Conclusions}

Assessing spasticity with the resource of scales is possible, however, lacks the necessary accuracy. The resource of an isokinetic dynamometer allows more precise and effective measurements for quantifying spasticity. This procedure offers good teste-retest reliability and it is easily applicable in a clinical context. Thus, the results of a clinical intervention can be verified and quantified making it possible to adapt treatment programs to the results obtained. Treatment efficacy can be measured calculating torque values before and after clinical interventions.

Spasticity assessment requires a definition of protocols considering both sampling and methods. The position of the participant, his understanding of the instructions, as well as specific details regarding PROMs, angular velocity and number of repetitions are definitive for the accuracy of measured values.

Concluding, isokinetic dynamometer is a valuable tool to address difficulties in assessing abnormal muscle tone, showing a high correlation with Ashworth scale results.

\section{Conflicts of Interest}

The authors declare no conflicts of interest regarding the publication of this paper.

\section{References}

[1] Sheean, G. and McGuire, J.R. (2009) Spastic Hypertonia and Movement Disorders: 
Pathophysiology, Clinical Presentation, and Quantification. PM and R, 1, 827-833. https://doi.org/10.1016/j.pmrj.2009.08.002

[2] Sheean, G. (2002) The Pathophysiology of Spasticity. European Journal of Neurology, Supplement, 9, 3-9. https://doi.org/10.1046/j.1468-1331.2002.0090s1003.x

[3] Larner, A.J. (2016) A Dictionary of Neurological Signs. Springer International Publishing, Berlin. https://doi.org/10.1007/978-3-319-29821-4

[4] Capelari, T.V., Borin, J.S., Grigol, M., Saccani, R., Zardo, F. and Cechetti, F. (2017) Evaluation of Muscle Strength in Medullar Injury: A Literature Review. Colunal Columna, 16, 323-329. https://doi.org/10.1590/s1808-185120171604179802

[5] Harb, A. and Kishner, S. (2020) Modified Ashworth Scale. StatPearls Publishing, Treasure Island.

[6] Ansari, N.N., Naghdi, S., Moammeri, H. and Jalaie, S. (2006) Ashworth Scales Are Unreliable for the Assessment of Muscle Spasticity. Physiotherapy: Theory and Practice, 22, 119-125. https://doi.org/10.1080/09593980600724188

[7] Akman, M.N., Bengi, R., Karatas, M., Kilinç, Ş., Sözay, S. and Özker, R. (1999) Assessment of Spasticity Using Isokinetic Dynamometry in Patients with Spinal Cord Injury. Spinal Cord, 37, 638-643. https://doi.org/10.1038/sj.sc.3100892

[8] Boudarham, J., et al. (2014) Relationship between Neuromuscular Fatigue and Spasticity in Chronic Stroke Patients: A Pilot Study. Journal of Electromyography and Kinesiology, 24, 292-299. https://doi.org/10.1016/j.jelekin.2013.11.006

[9] Moreau, N.G., Li, L., Geaghan, J.P. and Damiano, D.L. (2009) Contributors to Fatigue Resistance of the Hamstrings and Quadriceps in Cerebral Palsy. Clinical Biomechanics, 24, 355-360. https://doi.org/10.1016/j.clinbiomech.2009.01.012

[10] De Morton, N.A. (2009) The PEDro Scale Is a Valid Measure of the Methodological Quality of Clinical Trials: A Demographic Study. Australian Journal of Physiotherapy, 55, 129-133. https://doi.org/10.1016/S0004-9514(09)70043-1

[11] Supraja, M. and Singh, U. (2003) Study of Quantitative Assessment of Spasticity by Isokinetic Dynamometry. Indian Journal of Physical Medicine and Rehabilitation, 14, 15-18.

[12] Kakebeeke, T.H., Lechner, H., Baumberger, M., Denoth, J., Michel, D. and Knecht, H. (2002) The Importance of Posture on the Isokinetic Assessment of Spasticity. Spinal Cord, 40, 236-243. https://doi.org/10.1038/sj.sc.3101282

[13] Franzoi, A.C., Castro, C. and Cardone, C. (1999) Isokinetic Assessment of Spasticity in Subjects with Traumatic Spinal Cord Injury (ASIA A). Spinal Cord, 37, 416-420. https://doi.org/10.1038/sj.sc.3100849

[14] Perell, K., Scremin, A., Scremin, O. and Kunkel, C. (1996) Quantifying Muscle Tone in Spinal Cord Injury Patients Using Isokinetic Dynamometric Techniques. Paraplegia, 34, 46-53. https://doi.org/10.1038/sc.1996.8

[15] Hameau, S., Bensmail, D., Robertson, J., Boudarham, J., Roche, N. and Zory, R. (2014) Isokinetic Assessment of the Effects of Botulinum Toxin Injection on Spasticity and Voluntary Strength in Patients with Spastic Hemiparesis. European Journal of Physical and Rehabilitation Medicine, 50, 515-523. 